\title{
Long Space Missions and the Problem of Geomagnetic Deprivation of Human Population and Astronauts on the Earth, Moon and Mars
}

\author{
Alexander Trofimov ${ }^{*}$
}

\section{International Scientific Research Institute of Cosmic Anthropoecology, Novosibirsk, Russia}

\begin{abstract}
According to the data of some geophysicists [1-4], from the end of the XXth century the full vector of the magnetic field of the Earth, following jerks, periodic secular excursions, is gradually weakening. Accordingly the buffering properties of the Earth magnetosphere, which protects biosystems from excess solar proton-electron beams, are decreasing. Using modeled weakening of the geomagnetic field we had to answer the question: what are the possible biotropic consequences of heliophysical pressing for further human development?
\end{abstract}

The aim of the research was the prognostic evaluation of the possible genetically conditioned polyfunctional human reactions of healthy male volunteers (n-39) aged 18-20 years to repeated weakening of the magnetic field of the Earth and, if necessary, the development of preventive non-medicinal technologies.

Results. Significant differences $(\mathrm{P}<0.05)$ between volunteers in the experimental and control groups on the dynamics of electric, psychophysiological and other parameters, coupled with the appropriate genetic markers (genes D4, B1, TNF), and intensity of heliophysical factors at different stages of ontogeny of the examinees and their parents were showed .

The phenomenon of "heliophysical expression of genes", manifested at modeling of the short-term prolonged geomagnetic deprivation, was opened. It is shown, that drinking water "AquaHelios" has helioprotective properties and contributes to significant positive inversion of the functional dependence of many human functional systems on heliogeophysical impacts, increasing at geomagnetic deprivation. The necessity for the creation of a global system of geoecological human life support in conditions of spreading heliogeophysical changes of our biosphere and long space missions are scientifically substantiated.

Keywords: Geomagnetic fields (jerks and periodic excursions, long space missions, modeling of geomagnetic deprivation, heliophysical expression of genes, heliomagnetotropic human reactions, drinking water's prevention.

\section{INTRODUCTION}

The magnetic field of the Earth and its extremely important role in the maintenance and evolution of life on our planet at the end of the XXth - beginning of the XXIth century became the main object of scientific attention by collective of International Institute of Cosmic Anthropoecology (Russia, Novosibirsk) as an Observer responsible for Future, from the position of the strong anthropic principle of Carter Tsiolkovskii [5].

In the world scientific association the analysis of the secular variations of the geomagnetic field (GMF) is continued. One of the analytical schemes is represented in the work by Ron Chaar et al. [3], in which the distinct trend of geomagnetic induction weakening from the Xth century up to the modern period is seen.

There is a discussion of geophysical data on numerous jerks and excursions of the GMF, accompanied by a significant decrease in the intensity [1-3, 6-8], for example, with

*Address correspondence to this author at the International Scientific Research Institute of Cosmic Anthropoecology, Novosibirsk, Russia; Tel/Fax: +7 (383)332-40-68; E-mail: isrica2@ rambler.ru
Laschamp excursions, when it dropped by almost 10 times [9]. Discussion of the geophysical data concerning numerous jerks and excursions of the GMF, accompanied by a considerable decrease in its intensity [1-3, 6-8], as, for example in case of Laschamp excursions, when the intensity of the GMF decreased in almost 10 times [9], goes on.

The problem of the possible relationships between the magnetic inversions and the course of biological evolution is also discussed [4, 10-12]. With a decrease in the intensity of the GMF the buffer properties of the magnetosphere are reduced. It ceases to properly protect the biosphere from cosmic radiation: reinforced flows of cosmic rays start to penetrate into the atmosphere and cause a progressive increase in the number of secondary ionized particles that form the so called "broad atmospheric showers", reaching the biosphere.

Increased levels of radiation near the Earth`s surface in the periods of geomagnetic excursions can cause numerous genetic changes in biosystems, leading to significant evolutionary consequences [13-15]. In this case, mutagenic hard radiation from flashes of supernew stars is seen by some authors as a necessary condition for evolution; the GMF excursions can lead to mutations of regulatory genes (Tsakas, 
Table 1. Excursions, GMF inversions and events in human evolution

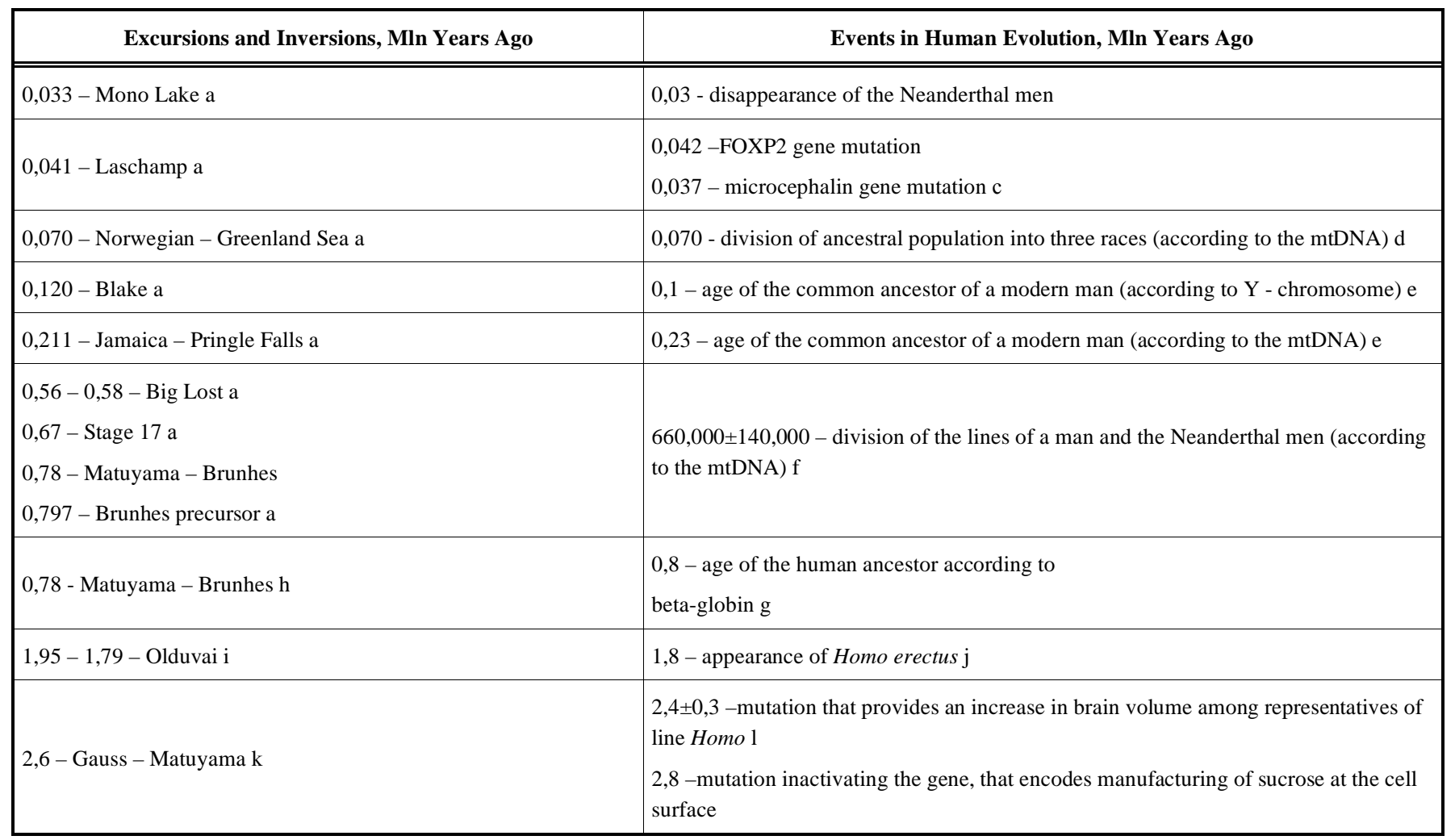

1984). Russian geophysics N.D. Kuznetcova and V.V. Kuznetcov in their works presented for discussion the comparative chrono-evolutionary analytical assessment of the possible dependence of genetic mutations of different types on a variety of geomagnetic inversions [4] (Table 1).

With the continued decrease in the intensity of the GMF biogeophysical study of its possible functionally-genetic, evolutionary consequences for a modern man and the search for the effective preventive means seems to be especially actual. That was the main motive and the purpose of the study.

\section{OBJECTIVES}

1. To study the dynamics of association of human psychophysiological parameters with the gene B1, with the length of the gene D4 alleles and the heliogeophysical situation at different stages of ontogeny of the volunteers' organisms at modeling of repeated weakening of the total vector of geomagnetic induction and transformation of its inclination.

2. To develop and to test the means of non-medicinal prevention of excess heliomagnetotropic human reactions on the basis of drinking water exposed to the weakened geomagnetic field.

\section{STUDY DESIGN}

While solving the problem1, ISRICA, together with the laboratory of helioclimatopathology of Scientific Centre of Clinical and Experimental Medicine of SB RAMS, have used the original shielding installations of YA Zaitsev` de- sign (patent of RF № 2012175 from 30.04.1994) with more than 500-fold weakening of the geomagnetic induction for the research [15]. In solving the 2nd problem small installations of the "TRODR" type weakening of the GMF more than 100 times (the authors: AV Trofimov, GI Druzhinin, 2011) $[15,16]$, used to exposure therein drinking water in order to give it heliomagnetoprotective properties broadcasted to a man (patent of RF № 2342149 from 27.12.2008), were created and tested.

The scheme of the works on the 1st stage of the study (2002 - 2005), held by "double blind" method, envisaged the 3 -month course of the 10 weekly sessions of 30 minutes for the male subjects aged $18-20$ years $(n=39)$ in the screening (1) and transforming (2) GMF installations.

At the 2nd stage (2001-2012), while solving the problem 2 , volunteers of the same age $(n=24)$ were investigated in the mode of their testing: in the period of the solar eclipse on July 22, 2009, when there was a redistribution of the flows of solar and galactic protons reaching the Earth's environs. Hemodynamic parameters of the subjects were measured twice: before and after taking in the various phases of the eclipse of $150 \mathrm{ml}$ of heliomagnetoprotective drinking water, prepared in a portable installation "TRODR", which, subsequently, became the prototype for a new generation of screening devices series "AquaHelios", intended for industrial production of helioprotective concentrate and waterbased beverages "AquaHelios" certified in Russia (ROSS certificate RU.AG79.HO4276, № 1162814 from 06.05.2013).

On the stage of 2002-2005 years the genotyping test was applied on the length of the alleles of D4 dopamine receptor gene, as well as on the genes B1 and TNF by the methods of 
PCP with primers flanking polymorphic regions of DNA (the joint fragment of work with the Institute of Therapy of SB RAMS and the Institute of Cytology and Genetics of SB RAS, conducted under the direction of now academician MI Voevoda).

Before-, in the middle and after the courses of the test, the computer registration of electroencephalographic, electro-light-psychophysiological, hemodynamic and gas discharge visualization's parameters of the volunteers, and also the assessment by the program "Helios" (Certificate of state registration in the Russian Federation № 970125 from 24.03.1997) of cosmic conditions in the period of prenatal development of the subjects, the so-called "phenomenon of heliogeophysical imprinting" largely determining the score of human health in his postnatal development, were conducted [17].

In the mathematical treatment the data of satellite monitoring (satellites «Goes» NACA, USA) of cosmic corpuscular proton-electron fluxes and multivariate correlation analysis on the program "Decision tree" (Institute of Mathematics of SB RAS, Berikov, 2002) (2) were used.

\section{RESULTS AND DISCUSSION}

1. The features of the distribution of the brain electrical potentials of the volunteers in conditions of the repeated short-term geomagnetic deprivation were revealed; it was noted a significant increase in activity in the range of the alpha rhythm (3) and it was shown that the heliogeophysical matrix, imprinted at different stages of prenatal development of the subjects, with the weakening of the geomagnetic induction appeared to be activated and more demanded.

It was noted the disclosure of the brain functional reserves: improvement of memory, concentration, and development of intellectual abilities, in particular, to abstract from the usual associations. By the end of the course of the simulated geomagnetic deprivation the manifested significant direct dependence of the level of mental processes on the intensity of the solar electrons and neutrons flows, as well as the significant reverse link with the value of the solar protons flows were revealed.

The higher nervous activity is realized through a large number of neurotransmitter systems of the brain that play an important role in the psychomotor and cognitive functions that are disturbed in multifactor diseases and conditions with a hereditary predisposition, such as Parkinson's disease, schizophrenia, substance abuse and others. Among the genes involved in the formation of the neuro-chemical human reactions, researchers pay especial attention to B1 gene and D4 dopamine receptors gene, allelic variants of which contain variable number (from 2 to 10) of imperfect repeats of DNA in the 3-d exon.

The study showed that the volunteers - carriers of short and long alleles of D4 gene react differently to geomagnetic deprivation [18], showing unequal sensitivity of human genetic substrate to the gradients of the magnetic field of the Earth.
With the use of meaningful models identified according to the covariance analysis (2) it was showed that the reactions to the geomagnetic deprivation depended on structurefunctional features of the genetic material (different length of the alleles of D4 gene, as well as genes B1 and TNF). According to these data, it can be assumed that with the weakening of the GMF, the increased genetic control over intellectual reserves of the brain not only neurophysiological, cardiovascular, hormonal et al. but cosmophysically dependent, stored in several related generations, occurs (Table 2).

We called this appearance opened for the first time as the phenomenon of "heliophysical expression" of genes [19], showing that the activation of previously "sleeping" genes is accompanied by a lowering of the thresholds of the human body's sensitivity to the weak information signals of cosmogonic content that have important evolutionary significance [12].

So, after a few sessions of the geomagnetic deprivation upon presentation of the information-holographic signals to the examinees (RF patent № 2239860 from 10.11.2004) it was noted a significant effect of the gene's expression on the spectrum of the EEG parameters (Table 3) and a significant effect of the D4 gene allele's length, in conjunction with the prenatally imprinted heliophysical impacts on the parameters of human magnetosensitivity, electroconductivity of TR (acupuncture points), the light absorption of the skin, the rheography parameters of the brain and on intellect, memory and creativity (Table 4) [19]. Later, in 2005-2007 studies we have noted other possible consequences of redistribution of the solar-functional dependencies in conditions of the weakening of the GMF: with the use of the same screening installation it has been shown that after a short term geomagnetic deprivation (in vitro) of blood samples of volunteers (healthy and patients with hypertension) significant associations of hemorheological and heliogeophysical parameters that increase the risk of cardiovascular catastrophes are revealed [20].

2. The results of the 1st stage of the research made even more urgent the search for such non-medicinal means that would ensure the protection of the biosphere, a man and the entire civilization in conditions of increasing onslaught of galactic and solar-corpuscular flows with the weakening of the protective magnetosphere cover. Unfortunately until recently there were no such effective means.

The development of the heliomagnetoprotective means on basis of water (RF patent № 2342149) in 2008 appeared to be perspective for this purpose. Drinking water treated in the weakened geomagnetic field, proved capable to protect the water structures of the human body, and, consequently, all its functional systems in the periods of solar-magnetospheric disturbances.

The first tests of helioprotective water were conducted in the period of extreme heliogeophysical situation - during one of the solar eclipses in 2009 , under which generally component of galactic cosmic rays increases and solar proton flow, reflected by the moon decreases. Corpuscular flows, redistributed by the Moon subsequently reach the magnetosphereionosphere layer of the protective shell of our planet, where, usually, their energy is significantly reduced. 
Table 2. The impact of "heliotransparency" on the genetically conditioned dynamics of the physiological parameters in the conditions of the modeling preformation of the geomagnetic field (the weakening of the GMF, the change of the angle of its slope) during prenatal ontogenesis.

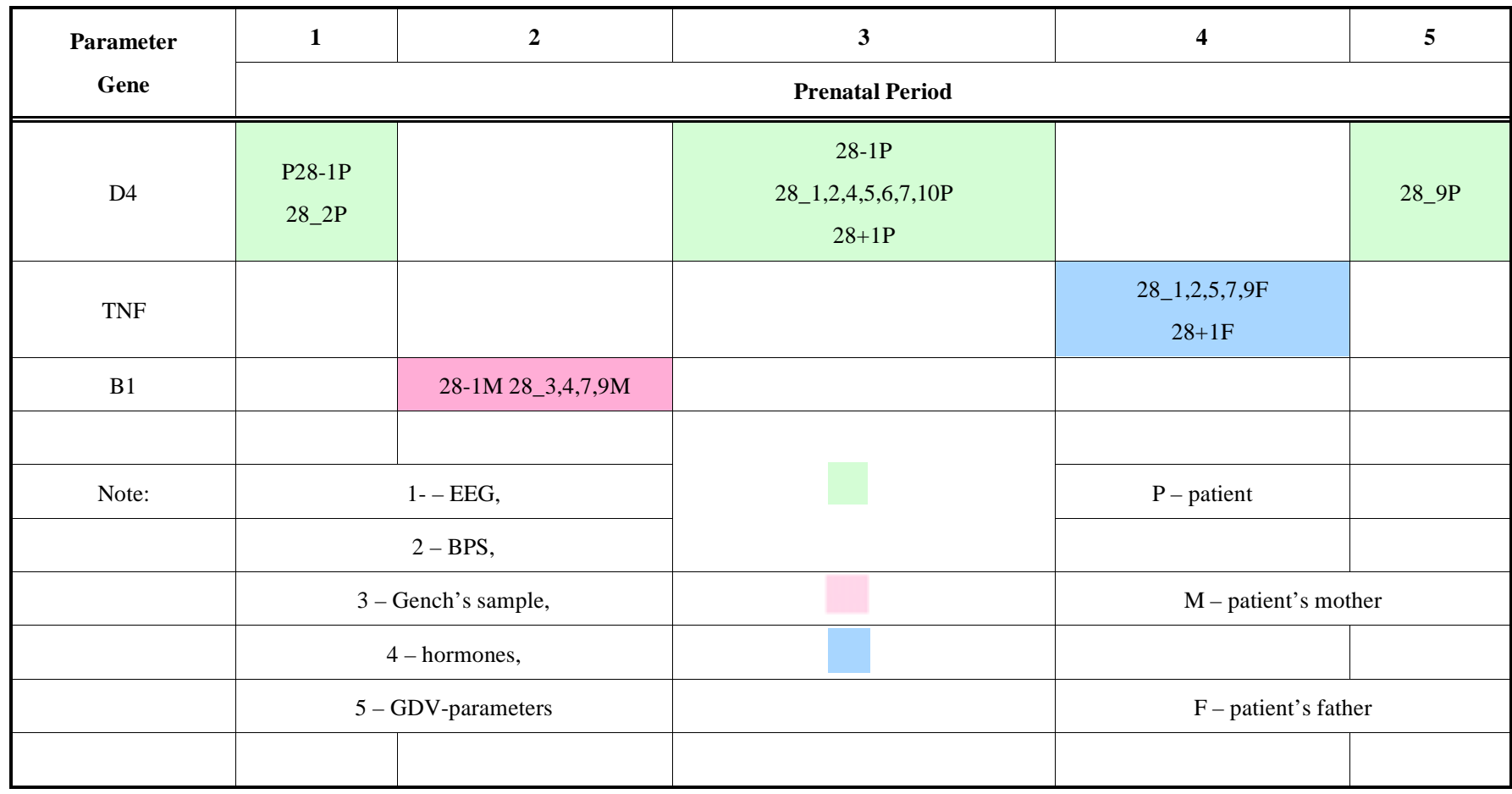

Notes: 1-electroencephalography (EEG), 2-blood pressure systolic (BPS), 3-Gench's sample,4-hormones, 5- gas discharge visualization (GDV), 28_1,2..28+1: periods pre- postnatal development

Table 3. Changes in the spectrum of EEG parameters at the prolonged geomagnetic deprivation, depending on the length of gene D4 alleles in the healthy examinees.

\begin{tabular}{|c|c|c|c|c|c|c|c|c|c|}
\hline \multirow{2}{*}{ Date } & \multirow{2}{*}{ Load Type } & \multicolumn{4}{|c|}{ Amplitude } & \multicolumn{4}{|c|}{ Frequency } \\
\hline & & Delta & Teta & Alpha & Beta & Delta & Teta & Alpha & Beta \\
\hline \multirow{3}{*}{$12-13.11 .2002$} & control & - & - & - & - & - & - & - & - \\
\hline & Hologram 1 & - & $\mathrm{O} 2, \mathrm{Cz}$ & - & - & $\mathrm{Cz}$ & - & - & - \\
\hline & Hologram 2 & $\mathrm{~T} 4$ & $\begin{array}{c}\mathrm{F} 3, \mathrm{~T} 3 \\
\mathrm{Cz}\end{array}$ & - & $\mathrm{T} 3$ & - & $\begin{array}{c}\mathrm{T} 3, \mathrm{O} 1 \\
\mathrm{Cz}\end{array}$ & - & - \\
\hline \multirow[b]{2}{*}{$3-4.12 .2002$} & control hologram & - & - & - & - & - & - & - & - \\
\hline & hologram 1 & - & $\mathrm{T} 3$ & $\mathrm{Cz}$ & $\mathrm{T} 4$ & $\mathrm{~T} 3$ & $\begin{array}{l}\text { T3, T4, } \\
\mathrm{O} 2, \mathrm{Cz}\end{array}$ & - & - \\
\hline
\end{tabular}

Table 4. Peculiarities of covariative dependence of the geno-phenotypical signs, psychophysiological parameters of a man, and the cosmophysical environment (according to the data of Berikov V.B., 2002).

\begin{tabular}{|c|c|c|c|}
\hline № & \multicolumn{2}{|c|}{ Coupled Parameters } & Cosmic Rays \\
\hline \hline 1 & gene B1 & intellect & electrons \\
\hline 2 & gene B1 & memory & neutrons \\
\hline 3 & & digital test & protons (Pr>1 keV $),$ \\
$(\operatorname{Pr}>10 \mathrm{keV})$
\end{tabular}


Table 4. contd..

\begin{tabular}{|c|c|c|c|}
\hline № & \multicolumn{2}{|c|}{ Coupled Parameters } & Cosmic Rays \\
\hline \hline 5 & $\begin{array}{c}\text { M-test } \\
\text { (electroconductivity TR) }\end{array}$ & memory & neutrons \\
\hline 6 & operative memory & creative work & protons (Pr>1 keV), \\
\hline 7 & $\begin{array}{c}\text { M-test } \\
\text { (paulse, APs) }>10 \mathrm{keV})\end{array}$ & alpha particles \\
\hline 8 & reographic index & protons (Pr>1 keV), \\
\hline 9 & Light absorption & $(\operatorname{Pr}>30 \mathrm{MeV})$ \\
\hline 10 & tolerance to physical load & neutrons \\
\hline
\end{tabular}

Table 5. Correlation dependences of physiological parameters on the five-minute values of the electrons, protons, neurons, and $X$ rays in the second group (Novosibirsk) in the 3rd metering.

\begin{tabular}{|c|c|c|c|c|c|c|c|}
\hline & $\begin{array}{l}\operatorname{Pr}>1 \\
\mathrm{MeV}\end{array}$ & $\begin{array}{l}\operatorname{Pr}>10 \\
\mathrm{MeV}\end{array}$ & $\begin{array}{l}\operatorname{Pr}>100 \\
\text { MeV }\end{array}$ & $\begin{array}{c}\mathrm{El}>\mathbf{0 , 6} \\
\mathrm{MeV}\end{array}$ & $\begin{array}{l}\mathrm{EI}>2 \\
\mathrm{MeV}\end{array}$ & $\mathrm{Ne}$ & X-Rays \\
\hline systolic pressure & 0,23 & 0,23 & 0,31 & 0,23 & 0 & 0,23 & $-0,25$ \\
\hline $\begin{array}{l}\text { diastolic } \\
\text { pressure }\end{array}$ & 0,53 & 0,53 & $0,54^{*}$ & 0,53 & 0 & 0,53 & $-0,26$ \\
\hline IM & $-0,03$ & $-0,03$ & $-0,08$ & $-0,03$ & 0 & $-0,03$ & $-0,15$ \\
\hline heart rate & 0,13 & 0,13 & 0,29 & 0,13 & 0 & 0,13 & $-0,28$ \\
\hline tone & $-0,44$ & $-0,44$ & $-0,33$ & $-0,44$ & 0 & $-0,44$ & 0,02 \\
\hline \multicolumn{8}{|c|}{$\begin{array}{c}\text { Correlation dependences of physiological parameters on the five-minute values of the electrons, protons, neurons, and X-rays in the second group (No- } \\
\text { vosibirsk) in the } 4 \text { th metering. }\end{array}$} \\
\hline & $\begin{array}{l}\operatorname{Pr}>1 \\
\mathrm{MeV}\end{array}$ & $\begin{array}{c}\operatorname{Pr}>10 \\
\mathrm{MeV}\end{array}$ & $\begin{array}{c}\mathrm{Pr}>100 \\
\mathrm{MeV}\end{array}$ & $\begin{array}{c}\mathrm{El}>0,6 \\
\mathrm{MeV}\end{array}$ & $\begin{array}{c}\mathrm{El}>2 \\
\mathrm{MeV}\end{array}$ & $\mathrm{Ne}$ & X-Rays \\
\hline systolic pressure & $-0,16$ & $-0,16$ & $-0,12$ & $-0,16$ & 0,34 & $-0,06$ & 0,17 \\
\hline $\begin{array}{c}\text { diastolic pres- } \\
\text { sure }\end{array}$ & $-0,39$ & $-0,39$ & $-0,64 *$ & $-0,39$ & $-0,13$ & $-0,11$ & $-0,32$ \\
\hline $\mathrm{IM}$ & 0,53 & 0,53 & 0,29 & 0,53 & $-0,30$ & 0,34 & 0,52 \\
\hline heart rate & 0,42 & 0,42 & $-0,03$ & 0,42 & $-0,34$ & 0,32 & 0,31 \\
\hline tone & $0,60^{*}$ & $0,60 *$ & 0,27 & $0,60^{*}$ & $-0,45$ & 0,14 & 0,29 \\
\hline
\end{tabular}

*The significance of the correlation coefficient $(\mathrm{p}<0,05)$.

It was shown that a significant $(\mathrm{P}<0.05)$ direct dependence of the human vascular tone, estimated by the diastolic blood pressure value on the flow of electrons and protons of different energy occurring in the period after the eclipse $\left(3^{\text {rd }}\right.$ metering, the Table 5), when receiving a small amount of helioprotective drinking water already in 20-30 minutes positively transformed. In the volunteers, who consumed the water, significant $(\mathrm{P}<0.05$ for protons with energies above $100 \mathrm{meV}$ ) inverse correlation of diastolic blood pressure with corpuscular flows of high energies was revealed $\left(4^{\text {th }}\right.$ metering, the Table 5).
Recent studies conducted in the Far North in regime of testing of healthy subjects [21] and volunteers with hypertension who expressed their consent to pass (by double "blind" method) 2-3 - week courses with the use of control and geomagnetically-deprived drinking water, confirmed our first observations [16, 17]. Helioprotective water, which is from July 2013 produced in Russia under the name of a drink "AquaHelios" can provide a long-term and effective protection of the functional systems of human body in the periods of solar-magnetospheric disturbances. 


\section{CONCLUSION}

1. In conditions of a simulated weakening of the geomagnetic field, more than 500 times, the phenomenon of "heliophysical gene expression" is revealed: significant associations of the parameters that reflect the functional activity of the brain, the state of psychophysiological, intellectual and creative processes with genetic markers (genes B1 and D4) and heliophysical situation in the pre-and postnatal ontogeny of the examinees.

2. The heliophysical gene expression, manifested at the prolonged short-term geomagnetic deprivation of a man contributes to lowering the threshold of his sensitivity to the information-holographic signals of the cosmogonic content associated with the dynamics of electrophysiological parameters and the length of D4 gene alleles.

3. Jerks and secular excursions of the geomagnetic field, accompanied by the weakening of its induction and the increased access to the biosphere of solar-galactic corpuscular flows, increasing the measure of openness of biological systems can have evolutionary consequences for a man.

4. The non-medicinal means on the basis of drinking water treated in the weakened geomagnetic field, which reduces the excess heliomagnetotropic reactions of a man and promotes prevention of crisis states (on an example of patients with hypertension) was developed and successfully tested.

5. The necessity of geo-ecological life support on the Earth and Space in conditions of changing heliogeophysical environment, the ongoing reduction of the geomagnetic induction and the increased access of solar-galactic corpuscular flows to the biosphere was scientifically based.

6. Treatment of drinking water in the weakened geomagnetic field, in our opinion, leads to such changes in its nanoclusteral structure, energy-information capacity and biocatalytic activity that provide helioprotective effect in relation to a man on the supramolecular, cellular, systemic and organism levels.

\section{SUGGESTIONS}

1. It seems to be especially important to continue, in terms of new projects, multidisciplinary research of biotropic effects of the prolonged simulated geomagnetic deprivation of biosystems with the purpose to determine the range of possible evolutionary consequences of reducing the buffering properties of the geomagnetic field and the development of a global system of geo-ecological life-support of humanity and the astronauts in conditions of ongoing cosmoplanetary changes and long space missions to the Moon and Mars.

2. To approach this purpose it is promising to organize International Scientific Research Center "Cosmobiotron" that has large installations from new composite materials with varying degrees of screening the GMF and also a staff of highly qualified astrogeophysics, biologists, geneticists and physicians. Scientific research bases of the International Scientific Research Institute of Cosmic Anthropoecology in Russia, Novosibirsk and Krasnoyarsk may be the control points for the development of future project.
This material was presented on the 2-nd International Conference on Earth Science and Climate Change (July 2324, 2013, Las Vegas, NV, USA/ The abstract of the report «Geomagnetic deprivation- Modeling, Prognosis, Prevention» was published by Journal of Earth Science and Climate Change (July 2013, volume 4, issue 4, p.20) and 2:798, doi: $10 . .4172 /$ scientificreports. 798

\section{CONFLICT OF INTEREST}

The author confirms that this article content has no conflict of interest.

\section{ACKNOWLEDGEMENTS}

Academician Veail Kaznacheev, Academician M. Voevoda.

\section{REFERENCES}

[1] Kuznetsov VV. A model of virtual geomagnetic pole motion during reversals. Phys Earth Planet Inter 1999; 115: 173-9.

[2] Mandea M, Bellder E, Le Mouel J. A geomagnetic jerk for the end of the 20-th century. EPSL 2000; 183: 369-73.

[3] Shaar R, Ben-Yosef E, Ron H. Geomagnetic field intensity: how high can it get? How fast can it change? Constraints from Iron Age copper slag. Earth Planet Sci Lett 2011; 301: 297-306.

[4] Kuznetsova ND, Kuznetcov VV. The influence of cosmic radiation and the secular variations of the geomagnetic field on the evolution of life. Vestnik 2012; 2: 11-8.

[5] Carter B, Zelmanov AL, Idlis GI. Problem of search of life in the Universe. Moscow 1986.

[6] Guskova EG, Raspopov OM, Dergachev VA. Manifestation of the Gothenburg geomagnetic field excursion in the Barents Sea bottom sediments. Geomag Astron 2007; 47: 781-6.

[7] Harrson CG. Evolutionary processes and reversals of the Earth magnetic field. Nature 1968; 217: 46-7.

[8] Roberts A. Geomagnetic excursions: knows and unknows. Geophys Res Lett 2008; 35: 17307.

[9] Ferk A, Leonardi R. The Laschamp geomagnetic field excursion recorded in Icelandic lavas. Phys Earth Planet Inter 2009; 107: 1930 .

[10] Ambrose SH. Late Pleistocene human population. Bottlenecks, volcanic winter and differentiation of modern humans. J Hum Evol 1998; 34: 623-51.

[11] Kaznacheev VP, Dmitriev AN, Mingazov IF. Civilization in conditions of rising of energy capacity of the Earth`s natural processes: Problems of cosmonoospheric futurology. Novosibirsk: Nauka 2007.

[12] Trofimov AV. Modeling of the biotropic effects of secular geophysical changes: Proceedings of the X International Scientific Conference; October 2008; Almaty, Kazakhstan. J Prob Open Sys Evol 2008; 10: 139-48.

[13] Green RE. Malaspinas A-S.,Krause J. A complete neandertal mitochondrial genome sequence determined by high- through put sequencing. Cell 2008; 134: 416-26.

[14] Leonard WR, Snodrass JJ, Robertson ML. Effects of brain evolution of human nutrition and metabolisam. Ann Rev Nutr 2007; 27 : 311-27.

[15] Stedman HH, Kozyak BW, Nelson A. Myosin gene mutation correlates with anatomical changes in the human lineage. Nature 2004; 428: 415-18.

[16] Trofimov AV, Drujinin GI. Information hologram: theoretical and practical perspectives for ecology and medicine of XXI century. Krasnoyarsk: Polikor 2011.

[17] Trofimov A. Prenatal helioimprinting: new preventive technologies. Saarbrucken: Palmarium Academic Publishing 2012.

[18] Maximov VN, Ustinov SN, Devitsin DV. Polymorphism of the D4 dopamine receptor gene and magnetosensitivity of the human organism. Vestnik 2002; 9: 106-10. 
[19] Kaznacheev VP, Trofimov AV. Reflections on life and intelligence on planet Earth: problems of cosmo-planetary anthropoecology. Wasserburg: Academy for Future Sciences in Europe 2008.

[20] Trofimov AV, Sevostyanova EV. Heliogeophysical Aspects of Rheology: New Technologies and Horizons of Preventive Medicine. In: Durairaj R, Ed. Rheology: new concepts, applications and methods. Rijeka: INTECH 2013; pp. 39-56.
[21] Trofimov A, Hirch M. To the evolution of the polar electrojets influence on physiological parameters of a man at phonic conditions while using unmedical heliomagnitoprotective remedies: Proceedings of the 15th International Congress on Circumpolar Health; August 2012; Fairbanks, USA, 2012.

Received: May 20, 2014

(C) Alexander Trofimov; Licensee Bentham Open.

This is an open access article licensed under the terms of the Creative Commons Attribution Non-Commercial License (http://creativecommons.org/licenses/by-nc/3.0/) which permits unrestricted, non-commercial use, distribution and reproduction in any medium, provided the work is properly cited. 